\title{
Seçim Sonrası Dönemde Seçmenlerin Siyasal Memnuniyet ve Güven Düzeylerinin Belirlenmesine Yönelik Bir Araştırma
}

\author{
Mehmet Can Demirtaş ${ }^{1}$
}

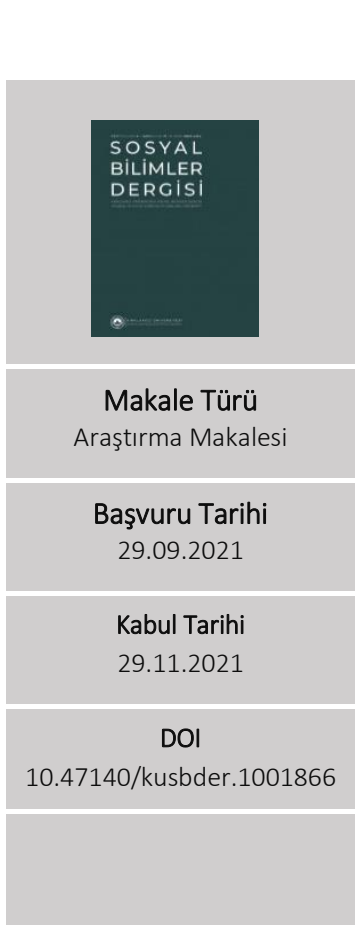

Öz

Siyasal pazarlama, siyasi partilerin ve adayların rakiplerinden daha yüksek oy seviyelerine sahip olmak, seçmen desteğini sağlamak ve yönetim dönemlerinde seçim öncesi seçmenlere sunduğu hedeflerine ulaşmak için sergilediği çabalardır. Siyasal pazarlamada başarı, siyasal pazara yönelik doğru ürün, fiyat, dağıtım ve tutundurma bileşenlerinin seçmen istek ve ihtiyaçlarına uygun planlanması ile elde edilmektedir. Dolayısı ile siyasal pazarlama çabalarının başarılı olması, seçmenler ile siyasi parti ya da adaylar arasında değer yönlü ve güven temelli değişimlerin yaratılmasına bağlıdır. Bu noktada siyasal güven olgusu, seçmenlerin siyasi parti ve adayların yönetim dönemlerinde doğru olanı yapacağına yönelik inançları olarak görülmekte ve siyasal pazardaki oyuncuların performans değerlendirme ölçütü olarak işlev görmektedir. Böylelikle siyasi parti ve adayların sürdürülebilir siyasal başarıları, seçmenlerin kendilerine yönelik algıladığı inandırıcılık ya da güvenilirlik düzeylerine bağlı olmaktadır. Bu çalışma, seçmenlerin siyasete yönelik güven ve memnuniyet düzeylerini tanımlamayı ve demografik nitelikler açısından aralarındaki ilişkiyi analiz etmeyi amaçlamaktadır. Bu amaca yönelik 340 seçmenin katılımı ile Kırklareli Illi'nde bir anket uygulaması gerçekleştirilmiştir. Çalışma sonucunda, seçmenlerin her ne kadar bir önceki dönem oy tercihlerinden memnuniyet duysalar da, siyasal güven düzeylerinin oldukça düşük olduğu bulgulanmıştır. Aynı zamanda seçmenlerin kurumlara ve siyasete yönelik güven düzeyleri ile siyasal memnuniyet algıları arasında demografik özellikler kapsamında anlamlı ilişkilerin mevcut olduğu tespit edilmiştir.

Anahtar sözcükler: Seçmen, Siyasal Güven, Siyasal Memnuniyet, Siyasal Pazarlama.

\footnotetext{
${ }^{1}$ Sorumlu Yazar: Dr. Öğr. Üyesi, Kırklareli Üniversitesi, İ.i.B.F., İşletme Bölümü, Üretim Yönetimi ve Pazarlama Anabilim Dalı, mehmetcan.demirtas@klu.edu.tr, https://orcid.org/ 0000-0002-4116-2415
} 


\title{
A Study on Determining Political Satisfaction and Trust Levels of Voters in the Post-Election Period
}

\author{
Mehmet Can Demirtaş ${ }^{2}$
}

\begin{abstract}

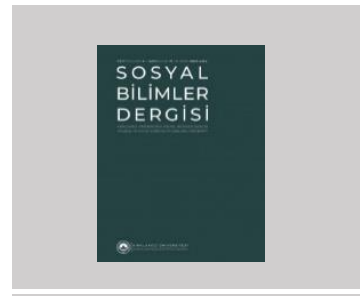

Article Type

Research Article

Submit Date

2021-09-29

Acceptance Date

2021-11-29

DOI

10.47140/kusbder.1001866

Political marketing is the efforts of political parties and candidates to have higher levels of votes than their competitors, to provide voter support, and to achieve the goals it presents to voters before the election. Success in political marketing is achieved by planning the right product, price, distribution and promotion components for the political market in accordance with voter needs and wants. Thus, the success of political marketing efforts depends on the creation of value-oriented and trust-based changes between voters and political parties or candidates. At this point, the phenomenon of political trust is seen as the belief that political parties and candidates will do the right thing during the administration periods and functions as the performance evaluation criteria of the players in the political market. Thus, the sustainable political success of political parties and candidates depends on the level of credibility or credibility perceived by voters. This study aims to define the trust and satisfaction levels of voters in politics and to analyze the relationship between them in terms of demographic characteristics. For this purpose a survey was conducted in Kırklareli province with the participation of 340 voters. As a result of the study, it was found that although the voters were satisfied with the voting preferences of the previous election period, their political trust levels were quite low. At the same time, it was seen that voters' trust in institutions and politics and their perceptions of political satisfaction had significant relationships with demographic characteristics.
\end{abstract}

Key words: Voter, Political Trust, Political Satisfaction, Political Marketing. 


\section{Giriş}

Seçmen tercihlerinin belirli bir siyasi parti ve aday lehinde şekillenmesinin sağlanması, her siyasi parti ve adayın rekabet ettiği siyasal pazar içindeki temel amacıdır. Siyaset sahnesinde var olan keskin rekabette başarı; seçmenlerin istek ve ihtiyaçlarının doğru belirlenmesine ve belirlenen istek ve ihtiyaçlara uygun çözüm önerilerinin sunulmasına bağlıdır. Dolayısı ile siyaset gibi "fikir" olgusunun zengin bir bileşen olduğu pazarlarda, belirli bir "idealin/fikrin" toplum tarafından talep edilmesini ve "fikrin" geniş kitlelerce benimsenmesini sağlamak için pazarlama biliminden yararlanılması gerekliliği söz konusu olmaktadır. "Siyasal pazarlama" olarak tanımlanabilen bu kavram; pazarlama bilimi ve siyaset biliminin öğretilerinin bir araya getirildiği ve akademik ilginin giderek arttığı bir alandır (Lees-Marshment, 2009, s. 1). Siyasal pazar alanına pazarlama ilke ve uygulamalarının adapte edilmesi olan bu sürecin temel hedefi topluma "umut sağlama" (Cwalina vd., 2011, s. 7) olarak görülmektedir. Toplumun ihtiyaç duyduğu alanlara yönelik çıktıların sağlanması için gerekli olan güç, yine seçmenlerden oluşan toplumun seçimler aracılığı ile vereceği karar doğrultusunda ortaya çıkacaktır. Dolayısı ile siyasi partiler ve adayların kendi fikirlerini, projelerini ve hedeflerini topluma en iyi şekilde açıklamaları başarı için ön koşuldur. Bu başarının sağlanması ise siyasal pazarlama çabalarının etkin bir şekilde yürütülmesine bağlıdır.

Siyasal pazarlama karmasının oluşturulmasındaki temel hedef; seçmenlerin ihtiyaç ve isteklerine uygun fikirlerin, sonuçların yaratılması ve dolayısı ile de seçmen memnuniyetinin sağlanmasıdır. Yönetim gücünün elinde tutulması hedefi siyasi parti ve adayları sürekli olarak seçmen memnuniyeti yaratma odağında çalışmaya itmektedir. Bu nedenle de seçmen memnuniyeti siyasal pazara yönelik stratejilerin belirlenmesinde odak olarak görülmektedir. Memnuniyet düzeyinin hem özel hem de siyasal alanda düşmesi, seçmenleri doğrudan alternatif arayışlara itmektedir. Aksine, seçmen memnuniyetinin sürekli olarak yüksek tutulması, seçmenlerin algıladığı siyasal fiyat bileşenleri baskısını azaltacak ve seçmenlerin siyasi parti ya da adayı çevrelerine övmelerini sağlayabilecektir (Tek, 2006: 181-182). Dolan ve diğerleri (2008: 97)'nin mutluluğa ilişkin gerçekleştirdiği literatür incelemesi sonucuna göre, bireylerin mutluluk seviyelerini etkileyen yedi boyutun varlığı söz konusudur. Bu boyutlar; "gelir", "kişisel özellikler", "sosyal özellikler", "zaman geçirme türleri", "kendisine/başkasına/yaşama yönelik tutum ve inançlar", "ilişkiler" ve "ekonomik, sosyal ve siyasi çevre"dir. Böylelikle "bireysel ekonomik durum" seçmen davranışlarına yönelik memnuniyet kapsamında değerlendirilmesi muhtemel bir faktör olarak görülebilmektedir (Demirtaş, 2015: 191).

Seçmenler; demokratik seçimler sürecinde siyasi parti, adaylar, ideoloji, parti programı, söz ve vaatler olarak tanımlanan ürünler arasından seçimlerini yapmaktadırlar. Seçmen 
tercihlerinin birçok faktörden etkilenerek oluşması ise, siyasal pazarlama karmalarının rasyonel temelde şekillendirilmesi önündeki sorunlar olarak görülmektedir. Siyasal ürünün seçmen tarafından tercih edilmesi sürecinde ortaya çıkan olumsuz etkenler, siyasi parti ya da adayların tüm iletişim çabalarının sonuçsuz kalmasına neden olabilmektedir. Oy verme kararına etki eden faktörleri her ne kadar tam ve kesin ifadeler ile belirlemek mümkün olmasa da birçok araştırma sonucunda üzerinde önemle durulan değişkenlerin "siyasal güven", "kişilik", "yerleşim yeri", "din", "değerler", "aile”, "referans grupları", "parti ile özdeşleşme"," "etnik kimlik", "demografi" olduğu görülmektedir (Lazarsfield vd, 1944, Campbell ve diğerleri, 1964, Yorke ve Meehan, 1986, Akgün, 2001; Dermody ve Lloyd, 2004; Li, 2004; Anderson ve Lotempio, 2002, Caprara ve diğerleri, 1990; Newman, 1999; Hibbing ve diğerleri, 2011; Özkiroz ve Moral: 2011; Nişancı ve Işık, 2012; Arnould vd, 2004). Seçmenlerin kararlarının şekillenmesinde sayılan değişkenler dışında birçok faktörün etkili olabileceği söz konusu olmakta ve özellikle vaatler seçmenlerin ilgisini yoğun olarak çekebilmektedir. Seçmenlerin seçim sonrası dönemde elde edecekleri tatmin düzeyi, belirtilen söz ve vaatlerin yerine getirilmesiyle sağlanan memnuniyet ile ortaya çıkacaktır. Dolayısı ile seçmenlerin siyasi parti ya da adaylara ilişkin algıladıkları siyasal güven ve memnuniyet düzeyinin yüksekliği, siyasal ürünün tercihindeki itirazları da engelleyecektir. Bu nedenle de seçmenlerin siyasal pazara ilişkin güven ve memnuniyet düzeylerinin belirlenmesi, seçim sürecine yönelik stratejilerin oluşturulmasına önemli stratejik katkılar sunabilecektir.

Bu çalışma seçim sonrası dönemde seçmenlerin siyasi parti ve adaylara yönelik algıladığı siyasal güven ve memnuniyet düzeylerini siyasal pazarlama bakış açısı ile analiz etme amacını taşımaktadır. Çalışma kapsamında siyasal güven ve siyasal pazarlama kavramları tanımlanmış ve belirlenen çalışma amacına ulaşmak için 31 Mart 2019 tarihinde gerçekleştirilen yerel seçim sonrasında Kırklareli ili'nde bir alan araştırması gerçekleştirilmiştir. Çalışma, elde edilen bulguların değerlendirilmesi, sonuç ve önerilerin sunulması ile tamamlanmıştır.

\section{Siyasal Güven}

"Siyaset bilimi literatüründe siyasal güven kavramının tanımı çok net değildir. Yerine göre "güven", "yaygın destek", ya da "halk desteği" kavramları da aynı anlamda kullanılmaktadır" (Akgün, 2001: 4). Stokes (1962) siyasal güveni "hükümete yönelik temel değerlendirme yönelimi" olarak tanımlamaktadır (Aberbach ve Walker, 1970: 1199). Miller ve Listhaug (1990) siyasal güveni, "siyasal sistemin vatandaşların taleplerine duyarlı olduğuna ve sürekli bir gözetim olmasa dahi sistemin doğru olanı yapacağına ilişkin kanaatlerin bir özeti” şeklinde tanımlamaktadır (Akgün, 2007: 118). Schiffman vd. (2010: 372-373) siyasal güveni; "yönetim biçimine olan güven", "siyasal kötümserlik/alaycılık" ve "görevde bulunan siyasetçilere güven" olmak üzere 3 başlıkta incelemektedir. Yazarlara göre, görevde bulunan siyasetçilere 
yönelik siyasal güven “ilişkisel güven”dir. Çünkü oluşması beklenen siyasal güven, görevde bulunan siyasetçinin faaliyetleri sonucu olumlu ya da olumsuz şekilde değişim gösterecektir.

"Siyaset ve güven arasındaki ilişki, siyasetin en çok irdelenen konularından bir tanesidir. Siyasete ve siyasetçilere karşı duyulan güvensizlik, çağdaş demokratik rejimlerin en sık karşılaştığı sorunlardan bir tanesi olarak göze çarpmaktadır. Türkiye'de değişik zamanlarda yapılan kamuoyu anketlerinde siyasetçiler ve parlamento en güvenilen kurumlar arasında genelde en son sıralarda kendisine yer bulabilmektedir. Siyasetçilere ve siyasal kurumlara duyulan güvenin düşük olması, sadece Türkiye'de değil; dünyanın en gelişmiş ülkelerinde de demokratik rejimler açısından sık karşılaşılan tehlikeli bir sorun olarak gözükmektedir" (Bingöl, 2009: 1). Mortimore (2003: 119) benzer şekilde bireylerin, siyasilere olan güven düzeyinin günümüzde herhangi bir kurumda çalışan profesyonellere ya da kamu ve özel sektör çalışanlarına duyulan güvene göre daha düşük olduğunu belirtmektedir. Siyasal güvene ilişkin literatürde siyaset bilimcilerinin ve siyasal pazarlama bilimcilerinin yoğunlaştığı noktalar; benzer şekilde toplumun ya da seçmenlerin siyasi adaylara ya da görevde bulunan siyasetçiye ve uygulanan politikalara, siyasal kampanya vaatlerinin sonuçlarına ve tabiki bağış toplama faaliyetlerine yönelik olarak ortaya çıkmaktadır (Schiffman vd, 2010: 372).

Shi (2001: 415)'ye göre "siyasal kültür" siyasal güvenin kilit bir belirleyicisidir ve bireylerin otoriteye yönelik tutumlarının şekillenmesinde, yaşadıkları ülkelerdeki yapı ve kurumlar önemli bir rol üstlenmektedir. Yazarın Çin ve Tayvan halklarının siyasal güven belirleyicilerini tanımlamaya yönelik gerçekleştirdiği çalışmasında, siyasal güvenin ortaya çıkmasında "hükümet performansının" Tayvan halkı için Çin halkına göre daha önemli olduğu sonucuna ulaşılmıştır. Siyasete yönelik güvensizliğin en temel göstergelerinden birisi seçimlere yönelik "seçmen katılım düzeylerinin azalması"dır. 2001 yılında gerçekleştirilen seçimlerde İngiltere halkının yaklaşık \%61'i oy kullanmamıştır. Bu durum üzerine yapılan açıklamaların ortak noktaları, genç seçmenlerin güven düzeylerinin düşük olması, güvensizlik ve olumsuz bakış açısına sahip olmaları gibi özellikler, önemli oranda genç seçmenin seçimlere yönelik politikalardan uzaklaşmasına neden olmuştur (Dermody ve Lloyd, 2004: 203). Li (2004: 234) siyasal güvenin belirleyicilerini; "hükümetin ekonomik ve siyasi performansı, siyasete yönelik olumlu politika deneyimleri ve siyasetçilerin sahip olduğu ahlak seviyesi" olarak belirtmektedir. Siyasal güvensizliğin Türkiye'deki en önemli nedeni ise halkın, "bir bütün olarak siyasal kurumların performansını yetersiz bulmalarıdır. Diğer önemli bir neden de vatandaşların, yönetim sürecinde yaygın adaletsizlikler ve haksızlıklar (rüşvet, adam kayırma, yolsuzluk vs.) olduğu inancından kaynaklanmaktadır. Yönetimin büyük çıkar gruplarının etkisi altında olduğu, sıradan vatandaşların etkisinin sınırlı kaldığı yönündeki kanaatler bireylerin sisteme olan güvenini aşındırmaktadır" (Akgün, 2007: 140). Anderson ve Lotempio (2002: 
348) siyasal güven ile seçim sonuçlarını ilişkilendirdiği araştırmaları sonucunda, seçimlerde kazanan adaylara oy veren seçmenlerin oy vermeyenlere göre daha yüksek bir siyasal güvene sahip olduğunu bulgulamışlardır. Bu tür bir siyasal güven oluşumu ise "kazanan etkisi" olarak açıklanmaktadır.

Literatürdeki çeşitli araştırmalarda seçmenlere sorulan "bir siyasi liderde bulunması gereken en önemli özellik nedir?" sorusuna verilen yanıtlar incelendiğinde; "dürüstlük", "güvenilir olma", "güvenirlilik", "söz ve vaatlerini yerine getirme" gibi değişkenlerin en sık karşılaşılan cevaplar olduğu görülmektedir (Uztuğ, 2004; Sitembölükbaşı, 2004; Özkiroz ve Moral, 2011; Demirtaş ve Orçun, 2015). Hatta siyasi rekabetin giderek artan şiddeti ve seçmenlerin sayılan özellikleri adaylarda görmek istemeleri sonucu siyasi partilerde aday belirleme sürecinde "dürüstlük" ve "güvenirlilik" özelliklerini öncelikli olarak aramaktadırlar (Demirtaş, 2014: 475). Seçmenlerin sadece siyasete olan güven düzeylerinin değil; aynı zamanda kurumlara (ordu, meclis, yargı), siyasi partilere, yerel meclislere, sosyal örgütlere ve medyaya yönelik güven düzeylerinin de belirlenmesi, siyasal kampanyaların başarılı olmasına katkı sağlayacaktır. Siyasal kampanyaların başarılı bir şekilde planlanabilmesi için seçmenlerin üzerine önem verdikleri konuları belirlemek amacıyla çok dikkatli bir "dinleme sürecine" girilmelidir. Bu süreç sonucunda aday ile seçmenleri ortak bir güven noktasına ulaştıracak konular belirlenmeli ve aday bu konulara yönelik güven kazandıracak açıklamaları gerçekleştirmelidir. Unutulmamalıdır ki, bir siyasi aday güvenilir olmak için toplumun önemli gördüğü her konuda açıklama yapmak zorunda değildir fakat seçilmesi durumunda hizmet edeceği potansiyel bireylerin ilgi duyduğu alanlarda yeterli düzeyde söz ve vaatlerini ortaya koymalıdır (Schiffman vd, 2010: 378). Siyasal güven olgusu özellikle çok kültürlü toplumlarda siyasilerin üzerinde önemle durması gereken bir ilgi alanını meydana getirmektedir. Siyasi iktidarların etnik ve ırk ayrımcılığında bulunması, siyasal güveni etnik gruplar arasında oldukça azaltmaktadır (Aberbach ve Walker, 1970; Fennema ve Tille, 1999). Böyle bir sorun yaşamamak için, etnik çeşitliliğin mevcut olduğu toplumlarda siyaset kurumu, demokrasinin tabana yayılımını sağlamaya yönelik pozitif siyasal güven algısı yaratmalıdır. Hollanda'da bulunan 4 etnik kimliğe (Türkler, Faslılar, Surinamlılar ve Antilliler) yönelik gerçekleştirilen siyasal güven araştırmasının sonucunda (Fennema ve Tillie, 1999: 709-711) Türklerin diğer etnik gruplarla karşılaştırıldığında daha yüksek düzeyde siyasal güven algısına sahip olduğu bulgusuna ulaşıımıştır. Yazarlara göre bu durumun ortaya çıkmasında; Türk seçmenlerin yerel politikaya ve seçimlere yüksek katılım göstermesi etkili olmaktadır.

Siyasal güvene yönelik önemli bir diğer nokta da seçmenler nezdinde yerel yöneticiler ile merkezi yöneticilere yönelik güven düzeylerinin farklılaşmasıdır. Seçmenler, demokratik seçimler ile merkezi hükümetleri belirledikleri gibi, yerel düzeyde de belediye başkanı / meclis üyeleri gibi yerel karar organlarını da belirlemektedir. Yerel yönetimlerden beklentiler ile 
merkezi yönetimden beklentiler her ne kadar birbirinden farklı olsa da içlerinden bir tanesine yönelik hissedilen memnuniyetsizlik, seçmenlerin siyasete olan güven düzeyini zedelemektedir. Ayrıca, unutmamak gerekir ki, bireyler herhangi bir kuruma yönelik yüksek düzeyde güven sahibi olabilirken; aynı kurumun yöneticisine karşı ise yüksek güvensizlik hissine sahip olabilmektedir. Bu nedenle, siyasal iktidarın siyasal güven düzeyini arttırması ancak bütünleşik bir güven inşası ile mümkün olabilecektir. Seçmenler ile uzun dönemli değer yönlü ilişki kurmak isteyen siyasi partiler için Sherman vd. (2012) "ilişkisel pazarlama" çabalarının kullanılmasının gerekli olduğunu vurgulamaktadır. "Siyasal ilişki pazarlaması" olarak ifade edilebilecek bu kavram, Henneberg ve O'Shaughnessy (2009: 12)'ye göre politikaların yayılmasını ve güven iletişiminin yaratılmasını sağlamaktadır. Örneğin Türkiye'de Milliyetçi Hareket Partisi "4446647" numaralı çağrı merkezini kurarak, seçmenlere doğrudan ulaşabilecekleri bir iletişim kanalı oluşturmasının ya da Adalet ve Kalkınma Partisini'nin her hafta vatandaşlara yönelik gerçekleştirdiği toplantıların temel amacı, ilişki derecesini yükselterek güven kazanmaktır.

Bir demokratik siyasi sistem toplumun çoğunluğunun desteği olmadan uzun süreli olarak yaşamaya devam edemez. Demokrasi, vatandaşların hükümetlerine duyduğu güvene bağlı olarak yaşamına devam eder. Bu güven düzeyi zarar gördüğü ya da azaldığı zaman, hükümetin yönetiminde bulunan tüm siyasi sistemin tehdit altına gireceği düşünülmektedir (Miller, 1974: 1001). Bu nedenle, demokrasinin ve siyasi sistemin işlerliğinin sürmesi için siyasi partiler ve adayların, seçmenler ile uzun dönemli ve güven temelli bir ilişki geliştirmeleri önerilmektedir.

\section{Yöntem}

Bu çalışmanın temel amacı; seçmenlerin siyasal güven düzeyleri ile memnuniyet seviyelerinin belirlenmesi ve siyasal pazarlama anlayışı kapsamında değerlendirilmesidir. Çalışmada bahsedilen siyasal güven olgusu; seçmenlerin siyasete ve siyaset dışı olarak tanımlanabilecek (yargı ve medya) kurumlara yönelik güven terimlerinden oluşmaktadır. Seçmenlerin algıladığı siyasal güven ile memnuniyet düzeylerinin belirlenmesi araştırmanın belirli bir olgunun güncel konumunu "tanımlayıcı" özellikte yapılandırılmasını sağlamaktadır.

Araştırmanın anakütlesini Kırklareli ili'nde seçmen olan bireyler oluşturmaktadır. Ancak tüm seçmenlere ulaşmanın yüksek maliyeti ve zaman kısıtlaması nedeniyle araştırma bir örneklem kapsamında planlanmıştır. Araştırma amacına uygun olarak örneklem Kırklareli ili'nde 31 Mart 2019 tarihindeki Mahalli idareler Genel Seçimi'nde oy kullanma hakkına sahip bireylerden oluşturulmuştur. Örneklem büyüklüğünün belirlenmesi sürecinde, 2019 yılında gerçekleştirilen Mahalli idareler Genel Seçimi'nde kayıtlı olan seçmen sayıları (http://www.ysk.gov.tr/doc/dosyalar/docs/2019Mahallildareler/II_Ilce_Secmen_Sandik_Say 
ilari.pdf Erişim Tarihi: 14/02/2021) göz önünde bulundurulmuştur. Kırklareli illi için 2019 yılı seçmen sayısı 72.489 olarak elde edilmiştir. Örneklem büyüklüğünün belirlenmesinde "n=Nt² p.q / $d^{2}(N-1)+t^{2} p . q "$ (Aytuğ ve Özgüven, 2011: 53) formülü uygulanmıştır. Örneklem büyüklüğü tespitinde güven düzeyi \% $95(t=1,96)$ ve belirli bir olayın gerçekleşme yüzdesi $(p)$ 84,37 olarak kabul edilmiştir. Formül sonucu elde edilen değer 202 olarak bulunmuş olsa da, örneklem hacminin daha yüksek sayılara ulaşması hedeflenmiş ve 340 seçmen ile uygulama gerçekleşmiştir. Araştırmanın alan çalışması 10/08/2021 - 22/08/2021 tarihleri arasında Kırklareli Merkez illçesi'nde kolayda örneklem yolu ile ulaşılan seçmenler ile gerçekleştirilmiştir. Her katılımcının gönüllük ilkesi ile soruları cevaplaması sağlanmış ve katılımcıların güven duymaları için özel hayata ilişkin herhangi bir ifade veri toplama aracına eklenmemiştir. Araştırmada belirtilen amaca yönelik bulguların değerlendirilmesinde hipotezlerden yararlanılmıştır. Araştırmanın hipotezleri ise şu şekildedir:

$\mathrm{H}_{1}$ : Seçmenlerin algıladığı siyasal güven düzeyi demografik nitelikler açısından anlamlı olarak farklılaşmaktadır.

$\mathrm{H}_{2}$ : Seçmenlerin kurumlara yönelik algıladıkları güven düzeyi demografik nitelikler açısından anlamlı olarak farklılaşmaktadır.

$\mathrm{H}_{3}$ : Seçmenlerin algıladıkları siyasal memnuniyet düzeyi demografik nitelikler açısından anlamlı olarak farklılaşmaktadır.

Araştırmanın verileri, araştırma amacına uygun olarak hazırlanan bir anket formu aracılığı ile toplanmıştır. Anket formunun hazırlanmasında; siyasal güven ve kurumlara yönelik güvene ilişkin ifadeler Anderson ve Lotempio (2002), Aberbach ve Walker (1970), Shi (2001), Li (2004), Akgün (2001, 2007) eserlerinden yararlanılarak elde edilmiştir. Siyasal memnuniyete yönelik ifadeler ise "genel ve yerel seçimdeki tercihlerden duyulan memnuniyet" kapsamında değerlendirilmiştir. Araştırmada kullanılan anket formu iki bölümden oluşmaktadır. Anketin birinci bölümünde; seçmenlerin genel yaşam koşulları ve siyaset kurumuna karşı algıladıkları memnuniyet seviyeleri, siyaset kurumuna yönelik güven düzeyleri ve genel siyasal koşullara yönelik algılarını belirlemeye ilişkin on yedi ifade bulunmaktadır. İkinci bölümde, demografik niteliklerine ilişkin ifadeler ile birlikte toplam 23 ifade ankette yer almaktadır. Araştırma verileri SPSS 20.0 paket programı aracılığı ile değerlendirilmiş olup, hata tespit edilen anketlerin çıkarılması sonucu 296 seçmene ait veriler ile istatistiki analizler gerçekleştirilerek bulgular yorumlanmıştır. Anketin birinci bölümündeki ifadeler 1-Kesinlikle Katılmıyorum...5Kesinlikle Katılıyorum aralığında, "Likert tipi” ölçek kullanılarak hazırlanmıştır.

Araştırma etik kurallara uygun olarak hazırlanmıştır. Bu hususta araştırmanın etik kurul onayı 10/09/2021 tarihinde Kırklareli Üniversitesi Bilimsel Araştırmalar ve Yayın Etiği Kurulu'nun E355235-302.99-21237 sayılı kararı ile elde edilmiştir. 


\section{Bulgular}

Çalışmanın bu bölümünde 296 seçmen ile gerçekleştirilen alan araştırması sonucu elde edilen verilere ilişkin bulgular sunulmaktadır. Çalışmada değerlendirilen ilk bulgu seçmenlerin demografik özelliklerine ilişkindir. İlgili değişkenlere ilişkin veriler Tablo 1'de gösterilmektedir.

Tablo 1. Seçmenlerin Demografik Özellikleri

\begin{tabular}{|c|c|c|c|}
\hline Değişken & Özellikler & $\mathrm{N}$ & $\%$ \\
\hline \multirow{2}{*}{ Cinsiyet } & Kadın & 129 & 44,5 \\
\hline & Erkek & 161 & 55,5 \\
\hline \multirow{2}{*}{ Medeni Hal } & Evli & 172 & 59,3 \\
\hline & Bekar & 118 & 40,7 \\
\hline \multirow{6}{*}{ Yaş } & $18-27$ & 92 & 32,3 \\
\hline & $28-37$ & 69 & 24,2 \\
\hline & $38-47$ & 51 & 17,9 \\
\hline & $48-57$ & 52 & 18,2 \\
\hline & $58-67$ & 12 & 4,2 \\
\hline & 68 ve üstü & 9 & 3,2 \\
\hline \multirow{6}{*}{ Gelir } & Gelirim Yok & 81 & 27,8 \\
\hline & Asgari Ücret ve altı & 58 & 19,9 \\
\hline & $2821 €-4000 €$ & 60 & 20,6 \\
\hline & 4001も-5000£ & 43 & 14,8 \\
\hline & $5001 €-6000 €$ & 19 & 6,5 \\
\hline & 6001£ ve üstü & 30 & 10,3 \\
\hline \multirow{5}{*}{ Eğitim } & İlköğretim & 64 & 22,7 \\
\hline & Lise & 99 & 35,1 \\
\hline & Ön Lisans & 38 & 13,5 \\
\hline & Lisans & 59 & 20,9 \\
\hline & Lisansüstü & 22 & 7,8 \\
\hline \multirow{7}{*}{ Meslek } & Kamu Çalışanı & 37 & 12,8 \\
\hline & Özel Sektör Çalışanı & 82 & 28,3 \\
\hline & Serbest Meslek & 36 & 12,4 \\
\hline & Emekli & 45 & 15,5 \\
\hline & Ev Hanımı & 23 & 7,9 \\
\hline & Öğrenci & 57 & 19,7 \\
\hline & İşsiz & 10 & 3,4 \\
\hline
\end{tabular}


Tablo 1 incelendiğinde; çalışmaya katılan seçmenlerin \%44,5’i kadın, \%55,5’i ise erkektir. Katılımcıların \%59,3'ü evli, \%40,7'si ise bekardır. Eğitim düzeyi açsından tablo değerlendirildiğinde, katılımcıların \%22,'si ilköğretim, \%35,1'i lise, \%13,5'i ön lisans, \%20,9'u lisans ve \%7,8'i de lisansüstü eğitim düzeyine sahiptir. Çalışmaya katılan seçmenleri incelendiğinde ise \%74,4'ünün 47 yaş ve altında yer aldığı, \%25,6'sının ise 48 ve üzeri yaşta olduğu görülmektedir. Gelir açııından konu ele alındığında; katılımcıların önemli büyüklükteki bir kısmının $(\% 27,8)$ gelir sahibi olmadığı, \%19,9'unun asgari ücret seviyesinde gelir elde ettiği, \%20,6'sının 2820も - 4000も, \%14,8'inin 4001も- 5000も, \%6,5'inin 5001も-6000も ve \%10,3'ünün ise 6001€ ve üstü gelire sahip olduğu görülmektedir. Demografik nitelikler açısından incelenen son özellikle ise meslek ile ilgilidir. Çalışmaya katılan seçmenlerin \%12,8'i kamu çalışanı, \%28,3’ü özel sektör çalışanı, \%12,4'ü serbest meslek sahibi, \%15,5'i emekli, \%7,9'u ev hanımı, \%19,7'si öğrenci ve \%3,4'ü ise işsiz olarak meslekleri değerlendirilmektedir.

Çalışmanın amacı açıklanırken de belirtildiği üzere, araştırma seçmenlerin algıladığı siyasal güven ve siyasal memnuniyet düzeylerinin belirlenmesine ilişkindir. Dolayısı ile ilgili olgunun tanımlanmasına yönelik seçmenlerin görüşlerinin değerlendirilmesi önem arz etmektedir. Seçmenlerin siyasal güven ve memnuniyet düzeyleri ile genel siyasal ve kişisel yaşamlarına ilişkin elde edilen bulgular aşağıda Tablo 2'de görülmektedir.

Tablo 2: Siyasal Güven, Kurumlara Güven ve Siyasal Memnuniyet

\begin{tabular}{llc}
\hline Seçmenlere Yöneltilen ifadeler & Ort & S.S. \\
\hline Siyasetçiler tarafından önemsendiğimi düşünüyorum. & 1,80 & 1,11 \\
\hline Siyasetçiler sözlerini çabuk unutmaktadırlar. & 3,96 & 1,37 \\
\hline Siyasetçilere güvenmiyorum. & 3,78 & 1,35 \\
\hline Siyasetçilerin seçmenlere karşı şeffaf olduğunu düşünüyorum. & 2,14 & 1,33 \\
\hline Bir seçmen olarak sadece seçim dönemleri hatırlanmaktan bıktım. & 4,09 & 1,24 \\
\hline Genel olarak ülkemizdeki siyasal atmosferden memnunum. & 1,94 & 1,26 \\
\hline Muhalafet partileri seçmenlerin fikirlerine önem vermektedir. & 2,38 & 1,25 \\
\hline Iktidar partisi seçmenlerin fikirlerine önem vermektedir. & 2,03 & 1,27 \\
\hline Son genel seçimde oy verdiğim siyasi partiden memnunum. & 3,24 & 1,42 \\
\hline Son yerel seçimde seçtiğim belediye başkanından memnunum. & 3,13 & 1,41 \\
\hline Önümüzdeki yerel seçimlerde oy kullanmayı düşünmüyorum. & 1,99 & 1,62 \\
\hline Türkiye'de medya bağımsızdır. & 1,78 & 1,24 \\
\hline Türkiye'deki adalet sistemine güveniyorum. & 1,77 & 1,14 \\
\hline
\end{tabular}




\begin{tabular}{lcc}
\hline Türkiye'de kadınlar ve erkekler eşit fırsatlara sahiptir. & 2,30 & 1,35 \\
\hline Hayatımdan memnunum. & 2,70 & 1,23 \\
\hline Hayatın giderek pahalılaşmakta olduğunu düşünüyorum. & 4,53 & 1,06 \\
\hline Ekonomik anlamda geçen seneye göre kendimi daha iyi hissediyorum & 1,76 & 1,16 \\
\hline
\end{tabular}

Tablo 2 kapsamında elde edilen tanımlayıcı istatistik değerler göz önüne alındığında, seçmenlerin siyasetçiler tarafından önemsenmediklerini $(\bar{x}=1,80)$, siyasetçilerin kendilerine karşı şeffaf davranmadığını $(\bar{x}=2,14)$, sadece seçim dönemlerinde hatırlanmaktan dolayı memnun olmadıklarını $(\bar{x}=4,09)$ dolayısı ile de siyasetçilere güven düzeylerinin oldukça düşük $(\bar{x}=3,78)$ gerçekleştiği görülmektedir. Ayrıca seçmenler, hem iktidar hem de muhalafet partilerinin kendi görüşlerine değer vermediklerini $(\bar{x}=2,38 ; 2,03)$ hissetmekte, böylelikle de ülkedeki genel siyasal atmosferden memnuniyet seviyeleri $(\bar{x}=1,94)$ düşük düzeydedir. Seçmenlerin bir sonraki seçim için oy kullanma yönünde eğilim gösterdikleri $(\bar{x}=1,99)$ ve bir önceki seçimlerde tercih edilen aday ya da siyasi partiden memnuniyet düzeylerinin $(\bar{x}=3,24$; $3,13)$ göreceli olarak olumlu konumda olduğu değerlendirilmektedir. Seçmenlerin ülkenin kurumsal yapısına ilişkin güven değerlendirmeleri için konu açıklanırsa, kadın-erkek fırsat eşitliği $(\bar{x}=2,30)$, medyanın bağımsızığı $(\bar{x}=1,78)$ ve adalet sisteminin işlerliğine $(\bar{x}=1,77)$ yönelik düşük düzey bir katılım söz konusudur. Seçmenlerin ekonomik görüşleri açısından genel memnuniyetleri incelendiğinde; kendilerini bir önceki seneye göre karşılaştırdıklarında ekonomik anlamda daha kötü hissettikleri $(\bar{x}=1,76)$, hayatın giderek pahalılaşmakta olduğu düşüncesinin hakim olduğu $(\bar{x}=4,53)$ ve böylelikle de hayatlarından duydukları memnuniyet seviyelerinin $(\bar{x}=2,70)$ de göreceli olarak düşük düzeyde gerçekleştiği görülmektedir.

Araştırmanın ilk bölümünde kullanılan 17 ifadenin yapı geçerliliğinin tespit edilmesi amacıyla faktör analizi uygulaması gerçekleştirilmiştir. Il gili analizde boyutların tespitinde "temel bileşenler yöntemi" kullanılmış olup, "Varimax" rotasyonundan yararlanılmıştır. Faktör analizi sürecine yönelik uygunluk için Kaiser-Meyer-Olkin testi (KMO) değeri göz önüne alınmış olup bu değerin 0,5'in üzerinde olması ve Barlett Küresellik test değerinin $p<0,05$ koşulu değerlendirilmiştir (Sipahi vd., 2006: 79). Analiz sürecinde güvenirlilik değerleri hesaplaması için alfa katsayıları değerlendirilmiş ve Özdamar (2004: 633) tarafından oluşturulan aralıklar çerçevesinde yorumlanmıştır. Seçmenlerin siyasal güven, kurumlara yönelik güven ve siyasal memnuniyet düzeylerine ilişkin düşüncelerini tanımlayan 17 ifadeye yönelik gerçekleştirilen faktör analizi bulguları Tablo 3'te gösterilmektedir. 
Tablo 3: Siyasal Güven, Kurumlara Güven ve Siyasal Memnuniyet Düzeylerine İlişkin Faktör Analizi

\begin{tabular}{|c|c|c|c|}
\hline Faktör Analizinde Yer Alan Ifadeler & 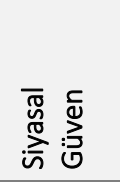 & 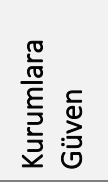 & 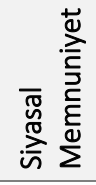 \\
\hline Siyasetçiler sözlerini çabuk unutmaktadır & ,832 & & \\
\hline Siyasetçilere güvenmiyorum & ,778 & & \\
\hline Bir seçmen olarak sadece seçim dönemleri hatırlanmaktan bıktım & 677 & & \\
\hline Türkiye'de medya bağımsızdır & & ,859 & \\
\hline Türkiye'deki adalet sistemine güveniyorum & & ,857 & \\
\hline Son genel seçimde oy verdiğim siyasi partiden memnunum & & & 881 \\
\hline Son yerel seçimde seçtiğim belediye başkanından memnunum & & & ,757 \\
\hline Açıklanan Varyans (\%) & 25,906 & 23,535 & 16,017 \\
\hline Kümülatif Açıklanan Varyans (\%) & 25,906 & 49,441 & 65,458 \\
\hline Güvenilirlik & ,846 & ,772 & ,724 \\
\hline Faktör Öz Değerleri & 2,184 & 1,321 & 1,077 \\
\hline $\mathrm{KMO}=0,736 ;$ Barlett $=282,099 ; \mathrm{df}=21 ; \mathrm{p}=0,000$ & & & \\
\hline
\end{tabular}

Tablo 3 incelendiğinde; 17 ifadede ölçümlenen seçmenlerin siyasal güven ve memnuniyet değerlendirmelerine yönelik gerçekleştirilen faktör analizi uygulaması sonucunda KMO değerinin ,736 ve Barlett Küresellik Testinin anlamlılık seviyesinin 0,05'in altında olduğu görülmekte ve böylelikle verilerin bu analize uygun olduğu anlaşılmaktadır. Analiz kapsamında 10 ifade birden fazla faktör grubunda bulunması ve güvenirlilik düzeylerini düşürmesi nedeniyle analiz dışı bırakılmıştır. Analiz sonucunda yedi ifadeden oluşan yapı üç boyuta indirgenmiş olup; üç boyut toplam varyanstaki değişimin \%65,45'ini açıklama yeteneğine sahip olmaktadır. Boyutlar ise sırasıyla "Siyasal Güven", "Kurumlara Güven" ve "Siyasal Memnuniyet" olarak tanımlanmıştır. Her üç boyuta ilişkin gerçekleştirilen güvenirlilik analizi sonucunda ise "siyasal güven" boyutunun $\alpha=, 846$, "kurumlara güven" boyutunun $\alpha=, 772$ ve "siyasal memnuniyet" boyutunun ise $\alpha=, 724$ değeri ile güvenilirliğinin oldukça yüksek olduğu tespit edilmektedir. Elde edilen boyutlara ilişkin tanımlayıc istatistik değerleri ise Tablo 4'te gösterilmektedir.

Tablo 4: Siyasal Güven, Kurumlara Güven ve Memnuniyet Boyutları Tanımlayıcı İstatistik Değerleri

\begin{tabular}{lll}
\hline Faktör Boyutları & Ort & S.S. \\
\hline Siyasal Güven & 2,05 & 1,01 \\
\hline Kurumlara Güven & 1,78 & 1,05 \\
\hline Siyasal Memnuniyet & 3,19 & 1,07 \\
\hline
\end{tabular}


Tablo 4 içerisinde belirtildiği üzere seçmenlerin siyasal güven algıları $(\bar{x}=2,05)$ ve kurumlara yönelik güven düzeyleri $(\bar{x}=1,78)$ oldukça düşüktür. Seçmenlerin siyasal memnuniyet seviyeleri ise $(\bar{x}=3,19)$ göreceli olarak yüksek ve bir önceki seçimdeki oy tercihlerinden memnun olma yönünde bir algıya sahip oldukları görülmektedir.

Araştırma hipotezlerinin test edilmesi amacıyla bağımsız örneklem t testi ve tek yönlü varyans analizi (Anova) testlerinden yararlanılmıştır. Seçmenlerin demografik niteliklerinin bağımsız değişken olarak kabul edildiği analiz sonuçları aşağıda Tablo 5’te gösterilmektedir.

Tablo 5: Siyasal Güven, Memnuniyet ve Kurumlara Güven Boyutlarına Yönelik Bağımsız Örneklem T ve Tek Yönlü Varyans Testi Sonuçları

\begin{tabular}{|c|c|c|c|c|c|}
\hline $\begin{array}{l}\text { Faktör } \\
\text { Boyutları }\end{array}$ & Cinsiyet & $\bar{x}$ & & $t$ & $p$ \\
\hline \multirow{3}{*}{$\begin{array}{l}\text { Siyasal } \\
\text { Memnuniyet }\end{array}$} & Kadın & 3,36 & & \multirow{2}{*}{2,326} & \multirow{2}{*}{0,021} \\
\hline & Erkek & 3,07 & & & \\
\hline & Medeni Hal & & & & \\
\hline \multirow{3}{*}{$\begin{array}{l}\text { Kurumlara } \\
\text { Güven }\end{array}$} & Evli & 1,88 & & \multirow{2}{*}{2,030} & \multirow{2}{*}{0,043} \\
\hline & Bekar & 1,64 & & & \\
\hline & Gelir & & $\bar{x}$ & $F$ & $\mathrm{p}$ \\
\hline \multirow[t]{2}{*}{$\begin{array}{l}\text { Siyasal } \\
\text { Memnuniyet }\end{array}$} & $\begin{array}{l}\text { Geliri Yok } \\
\bar{x}=3,49\end{array}$ & $\begin{array}{l}\text { 6001€ ve } \\
\text { üstü }\end{array}$ & 2,83 & 3,587 & 0,042 \\
\hline & Eğitim Düzeyi & & $\bar{x}$ & $\mathrm{~F}$ & $\mathrm{p}$ \\
\hline \multirow{2}{*}{$\begin{array}{l}\text { Kurumlara } \\
\text { Güven }\end{array}$} & \multirow{2}{*}{$\begin{array}{l}\text { İlköğretim } \\
\bar{x}=2,07\end{array}$} & Lisans & 1,50 & \multirow{2}{*}{3,502} & 0,017 \\
\hline & & Lisansüstü & 1,34 & & 0,033 \\
\hline
\end{tabular}

Tablo 5 incelendiğinde; seçmenlerin demografik özelliklerinin siyasal memnuniyet ve kurumlara güven boyutlarına yönelik algılamalarında anlamlı farklılıklar yarattığı görülmektedir. İlgili farklılıkların ilki cinsiyet değişkeni açısından siyasal memnuniyete ilişkindir. Cinsiyetin bağımsız değişken olarak kullanıldığı bağımsız örneklem t testi sonucuna göre, kadın seçmenler ile erkek seçmenlerin siyasal memnuniyet düzeyleri arasında anlamlı bir farklıık vardır. İlgili farklıı̆ın nedeni incelendiğinde; kadın seçmenlerin erkek seçmenlere göre daha yüksek bir siyasal memnuniyet düzeyine sahip oldukları görülmektedir. Siyasal memnuniyet boyutuna ilişkin elde edilen ikinci anlamlı farklılık gelir değişkeni kapsamında ortaya çıkmaktadır. Seçmenlerin gelir düzeyleri ile algıladıkları siyasal memnuniyet düzeyleri arasında anlamlı bir farklılık söz konusudur. İlgili farklılığın belirlenmesi amacıyla tek yönlü varyans analizi (Anova) ve gruplar arası anlamlı ilişkilerin tespiti için ise Post Hoc testleri içinden Tukey HSD testinden yararlanılmıştır. Elde edilen anlamlı farklılığın geliri olmayan 
seçmenler ile aylık 6001Ł ve üstü gelir elde eden seçmenler arasında ortaya çıktığı tespit edilmiş ve bu anlamlı ilişkinin nedenin ise geliri olmayan seçmelerin aylık 6001Ł ve daha fazla gelir sahibi seçmenlere göre daha yüksek siyasal memnuniyet hissetmelerinden kaynaklandığı belirlenmiştir. Demografik nitelikler itibariyle elde edilen üçüncü anlamlı farklıık kurumlara güven boyutu kapsamında medeni hal değişkeni açısından ortaya çıkmaktadır. Seçmenlerin medeni halleri kurumlara duyulan güven düzeyi açısından anlamlı bir farklıık yaratmaktadır. İlgili farklıı̆̆ın belirlenmesi için gerçekleştirilen bağımsız örneklem t testi soncuna göre; bekar seçmenler, evli seçmenlere göre kurumlara daha düşük düzeyde güvenmektedir. Kurumlara güven boyutu kapsamında elde edilen diğer bir anlamlı farklılık seçmenlerin eğitim düzeyleri itibarıyla elde edilmiştir. Kurumlara yönelik güven algısı seçmenlerin eğitim düzeyleri açısından anlamlı farklılık yaratmaktadır. Benzer şekilde farklılığın tespiti amacıyla tek yönlü varyans analizi ve gruplar arası anlamlı ilişkilerin tespiti için ise Tukey HSD testinden yararlanılmıştır. Gerçekleştirilen test sonuçlarına göre lisansüstü ve lisans eğitim düzeyindeki seçmenlerin kurumlara yönelik güven algılarının ilköğretim mezunu seçmenlere göre oldukça düşük tespit edilmesi ile anlamlı farklılık ortaya çıkmaktadır. Siyasal güven boyutuna ilişkin gerçekleştirilen analizlerde ise herhangi bir anlamlı farklılık tespit edilememiştir. Bu durum oldukça düşündürücü olmakla birlikte, çalışmaya katılan seçmenlerin demografik niteliklerinden bağımsız şekilde siyasete yönelik algılamalarının ortak bir noktada buluşması ve oldukça düşük bir seviyede gerçekleşmesi durumu söz konusu olmaktadır.

Bu sonuçlar göz önüne alındığında, " $\mathrm{H}_{1}$ : Seçmenlerin algıladığı siyasal güven düzeyleri demografik nitelikler açısından anlamlı olarak farklılaşmaktadır" hipotezi reddedilmiş olup, " $\mathrm{H}_{2}$ : Seçmenlerin kurumlara yönelik algıladıkları güven düzeyi demografik nitelikler açısından anlamlı olarak farklılaşmaktadır" ve " $\mathrm{H}_{3}$ : Seçmenlerin siyasal memnuniyet düzeyleri demografik nitelikler açısından anlamlı olarak farklılaşmaktadır" hipotezleri ise cinsiyet, medeni hal, eğitim ve gelir değişkenleri kapsamında elde edilen anlamlı ilişkiler nedeni ile kabul edilmiştir.

\section{Tartışma ve Sonuç}

Siyasi partilerin rekabet ettikleri siyasal pazarda iktidar olabilmeleri amacıyla üstlenecekleri çabaları açıklayan siyasal pazarlama, siyasal pazarda seçmenlerin tercihlerini şekillendiren önemli bir unsurdur. Bir siyasi partinin siyasal pazardaki başarısı, seçimlerde elde edeceği seçmen desteği ile orantılı olmakta ve ilgili seçmen desteğinin sağlanmasında anahtar rol ise "güven" kavramı ile ortaya çıkmaktadır. Seçmenlerin hissettiği siyasal güven düzeyi, siyasi partilerin söz ve vaatlerinin kabul görmesini de etkilediğinden, seçimlerde başarı elde etmek bir anlamda siyasal güvenin sağlanmasına bağlı olmaktadır. 
31 Mart 2019 tarihinde gerçekleştirilen Mahalli İdareler Genel Seçimi sonrası dönemde Kırklareli ili'nde 23 ifadeden oluşan bir anket aracılığı ile 296 seçmene ait verilerin değerlendirildiği bu çalışma, seçmenlerin siyasal güven ve memnuniyet düzeylerini tespit etmek ve demografik nitelikler itibariyle herhangi bir anlamlı farklıık olup olmadığını belirleme amacı taşımaktadır. Elde edilen veriler ışı̆̆ında seçmenlerin siyasete ve siyasetçilere yönelik oldukça düşük ve olumsuz algılamalara sahip olduğu tespit edilmiştir. Seçmenler, siyasetçilerin kendilerini önemsemediğini ve seçim öncesi açıklanan söz ve vaatlerin siyasetçiler tarafından çabuk unutulduğunu düşünmekte ve dolayısı ile siyasetçilere yönelik güven düzeyleri de oldukça düşük bir seviyede ortaya çıkmaktadır. Ek olarak seçmenler, siyasetçilerin kendilerine karşı şeffaf davranmadı̆̆ını, kendilerini sadece seçim dönemleri sürecinde hatırlamalarını da uygun görmediklerini belirtmektedir. Medya ve adalet sistemine yönelik algıları içeren kurumlara yönelik güven düzeyleri de siyasetçilere yönelik güven düzeylerine benzer şekilde oldukça düşük olarak bulunmuştur. Seçmenlerin siyasal güven ve kurumlara yönelik güven düzeylerinin oldukça düşük olarak gerçekleşmesine rağmen bir önceki seçimdeki oy tercihlerine ilişkin memnuniyet seviyeleri göreceli olarak yüksek seviyededir. Elde edilen bulgu Akgün (2007), Li (2004) tarafından gerçekleştirilen çalışma sonucu ile benzerdir. Aynı zamanda Anderson ve Lotempio (2002) eserinde seçim kaybetmiş adayın seçmenlerinin kazanan adayın seçmenlerine göre daha düşük güven düzeyine sahip olduğunu belirterek, siyasal güven olgusunun seçim sonuçları üzerinde önemli etkilerinin olduğunu da açıklamaktadır. Dolayısı ile seçmenler seçim öncesi dönemlerde belirli bir "umut" doğrultusunda oy vermekte ancak seçim sonrası dönemde umuda ilişkin fiziksel sonuçlar elde edemediğinde siyasal güvensizlik dolayısı ile de memnuniyetsizlik hissetmektedir. Bu nedenle seçmenlerin tercihlerinin belirli bir siyasi parti ya da aday lehine yönelmesinin önündeki en önemli faktörlerden birisi siyasal güvendir. Seçmenlerin güvendiği, inandığı ve söz ve vaatlerini yerine getireceğine dair şüphesinin olmadığı bir siyasal ürünün tercih edilmesinin önünde herhangi bir engel bulunmamaktadır. Siyasete yönelik güven düzeyi kadar kurumlara yönelik güven düzeyinin de seçmen memnuniyeti üzerinde etkili olduğu dolayısı ile ilgili kurumlara yönelik güven ve memnuniyet seviyelerinde de pozitif yönlü etki edeceği değerlendirilmektedir.

Sonuç olarak; gerçekleştirilen alan araştırması ile siyasal hayatın yönünü oyları ile belirleyen seçmenlerin siyasete, siyasetçilere, siyasi partilere ve kurumlara yönelik güven düzeylerinin oldukça düşük olduğu tespit edilmiştir. Bu nedenle seçim dönemleri öncesi ve sonrasını kapsamak üzere, siyasi partilerin ve adayların seçmenlere yönelik güven temelli bir "siyasal ilişkisel pazarlama yaklaşımı” uygulamaları, seçim öncesi dönemde güven zedeleyecek, ulaşılamayacak algısı yaratacak söz ve vaatlerden kaçınmaları gerekmektedir. Siyasal güvenin sağlanması için seçmenlere sürekli olarak faaliyetler ile ilgili bilgi verilmeli, açık şeffaf bir 
yönetim modeli tesis edilerek, seçmen katılımının sağlandığı görüşmeler ile seçmenlerde güven hissi yaratılmalıdır.

$\mathrm{Bu}$ çalışma siyasal güven ve memnuniyet olgusunu siyasal pazarlama kapsamında değerlendirerek çeşitli bulgular ışığında öneriler sunmaktadır. Konunun farklı değişkenler ve alan araştırmaları ile desteklenmesi ile hem çalışma alanın güncelliğinin korunmasına hem de alana ilişkin bilgi düzeyinde derinlik yaratılmasına olanak sağlanacağı düşünülmektedir.

\section{Makalenin Araştırma ve Etik Beyanı Bilgileri}

$\begin{array}{ll}\begin{array}{l}\text { Yazar Çıkar } \\ \text { Çatışması Beyanı }\end{array} & \begin{array}{l}\text { Araştırmaya konu olan durum ve olgular ile yazar arasında herhangi bir } \\ \text { çıkar çatışması bulunmamaktadır. }\end{array} \\ \begin{array}{l}\text { Yazar Katkı Oranı } \\ \text { Beyanı }\end{array} & \begin{array}{l}\text { "Seçim Sonrası Dönemde Seçmenlerin Siyasal Memnuniyet ve Güven } \\ \text { Düzeylerinin Belirlenmesine Yönelik Bir Araştırma" isimli makalenin tüm } \\ \text { bölümleri tarafımca yazımıştır. }\end{array} \\ \begin{array}{l}\text { Etik Kurul Onay } \\ \text { Belgesi }\end{array} & \begin{array}{l}\text { Araştırmanın etik kurul onayı 10/09/2021 tarihinde Kırklareli Üniversitesi } \\ \text { Bilimsel Araştırmalar ve Yayın Etiği Kurulu'nun E-355235-302.99-21237 } \\ \text { sayılı kararı ile elde edilmiştir. }\end{array}\end{array}$

\section{Kaynakça}

Aberbach, J. D., \& Walker, L. J. (1970). Political Trust and Racial Ideology. The American Political Science Review, 64(4), 1199-1219.

Akgün, B. (2001). Türkiye'de Siyasal Güven: Nedenleri ve Sonuçları. Ankara Üniversitesi S.B.F. Dergisi, 56(4), 1-23.

Akgün, B. (2007). Türkiye'de Seçmen Davranışı, Partiler Sistemi ve Siyasal Güven (2. b.). Ankara: Nobel Yayınları.

Aldemir, C., \& Bayraktaroğlu, G. (2004). Determining Effect of Personality Traits on Voter Behaviour Using Five Factor Personality Inventory. Journal of Faculty of Business, 5(2), 129-147.

Alvarez, M. R., \& Bedolla, L. G. (2003). The Foundations of Latino Voter Partisanship: Evidence from the 2000 Election. The Journal of Politics, 65(1), 31-49.

Anderson, C. J., \& Lotempio, A. J. (2002). Winning, Losing and Political Trust in America. B. J. Pol. S, 32(1), 335-351.

Arnould, E., Linda P., \& Zinkhan G. (2004). Consumer (2. b.). Mc Graw Hill.

Aytuğ, S., \& Özgüven, N. (2011). Pazarlama Yönetimi. Ankara: Detay Yayıncılık. 
Bayraktaroğlu, G. (2002). Politik Yaşamda Pazarlama Yaklaşımları. Süleyman Demirel Üniversitesi i.i.B.F Dergisi, 7(2), 159-168.

Bone, A. H,. \& Ronney, A. (1971). Politics and Voters (3. b.). McGraw Hill.

Campbell, A., Converse, P. E., Miller, W. E., \& Stokes, D. E. (1964). The American Voter. John Wiley \& Sons.

Bingöl, Y. (2009). Siyaset ve Güven İlişkisi: Bingöl ilii Örneğinde 1950-2007 Genel Seçimleri Üzerine Karşılaştırmalı Bir Analiz. Kocaeli Üniversitesi Sosyal Bilimler Enstitüsü Dergisi, 17(1), 1-27.

Caprara, G. V., Barbaranelli, C., \& Zimbardo, P. G. (1990). Personality Profiles and Political Parties. Political Psychology, 20(1), 175-197.

Cwalina, W., Falkowski, A., \& Newman, B. (2008). A Cross Cultural Theory of Voter Behaviour. New York: The Howarth Press.

Dermody, J., \& Lloyd, S. H. (2004). Segmenting Youth Voting Behaviour Through TrustingDistrusting Relationships: A Conceptual Approach. International Journal of Nonprofit and Voluntary Sector Marketing, 9(3), 202-217.

Demirtaş, M. C. (2014, Mayıs 8-10). Siyasi Partilerin Yerel Örgütlerinin Pazarlama Çabaları:

Yerel Seçimlere Yönelik Bir Araştırma. 13. Ulusal İ̧̧letmecilik Kongresi, 471-482. Antalya.

Demirtaş, M. C., \& Orçun, Ç. (2015). Siyasal Pazarlama Uygulamalarının Illk Kez Oy Kullanacak Seçmenler Üzerindeki Etkilerine Yönelik Bir Araştırma. KMÜ Sosyal ve Ekonomik Araştırmalar Dergisi, 17(28), 41-48.

Denver, D. (1994). Elections and Voting Behaviour in Britain. Harvester Wheatsheaf.

Dolan, P., Peasgood, T., \& White, M. (2008). Do We Really Know What Makes Us Happy? A Review of the Economic Literature on the Factors Associated with Subjective WellBeing. Journal of Economic Psychology, 29(1), 94-122.

Fennema, M., \& Tillie, J. (1999). Political Participation and Political Trust in Amsterdam: Civic Communities and Ethnic Networks. Journal of Ethnic and Migration Studies, 25(4), 703-726.

Henneberg, S. C. M., \& O’Shaughnessy, N. J. (2009). Political Relationship Marketing: Some Macro / Micro Thoughts. Journal of Marketing Management, 25(1/2), 5-29.

Hibbing, M. V., Ritchie, M., \& Anderson, M. R. (2011). Personality and Political Discussion. Political Behaviour, 33, 601-624.

Inglehart R., \& Norris, P. (2000). The Developmental Theory of the Gender Gap: Women's and Men's Voting Behavior in Global Perspective. International Political Science Review, 21(4), 441-463. 
İslamoğlu, A. H. (2002). Siyaset Pazarlaması Toplam Kalite Yaklaşımı (2. b.). İstanbul: Beta Yayınları.

Jeffress, L. W. (1999). The Impact of Ethnicity and Ethnic Media on Presidential Voting Patterns. Journalism and Communication Monographs, 1(3), 199-262.

Kotler, P., \& Sidney J. L. (1969). Broadening The Concept Of Marketing. Journal of Marketing, 33(1), 10-15.

Lazarsfield, P. F., Berelson, B., \& Gaudet, H. (1944). The People's Choice: How the Voter Makes Up His Mind in a Presidential Campaign. New York: Columbia University Press.

Lees-Marshment, J. (2009). Political Marketing Principles and Applications. Routledge.

Li, Lianjiang. (2004). Political Trust in Rural China. MODERN CHINA, 30(2), 228-258.

Miller, A. H. (1974). Rejoinder to "Comment" by Jack Citrin: Political Discontent or Ritvalism. American Political Science Review, 68(3), 989-1001.

Mondak, J. J., \& Karen D. Halperin. (2008). A framework for The Study of Personality and Political Behaviour. British Journal of Political Science, 38(2), 335-362.

Mucuk, İ. (2014). Pazarlama ilkeleri, (20.b .). İstanbul: Türkmen Kitabevi.

Nakip, M. (2003). Pazarlama Araştırmalarına Giriş. Ankara: Seçkin Yayıncılık.

Newman, B. I. (1999). Hanbook of Political Marketing. Thousand Oaks, Sage.

Niffenegger, P. B. (1989). Strategies For Success From Political Marketers. The Journal of Consumer Marketing, 6(1), 45-51.

Nişancı, Ş., \& Işık, C. (2012, Ekim 1-2). Etnisite Algısının Siyasal Tercihler Üzerine Etkisi: Kars

İli Kağızman İlçesi Üzerine Bir Araştırma. 2. Bölgesel Sorunlar ve Türkiye Sempozyumu.

Özdamar, K. (2004). Paket Programlar ile istatistiksel Veri Analizi (5. b.). Eskişehir: Kaan Kitabevi.

Özkiroz, A., \& Moral, S. (2011). Lider Özelliklerinin Seçmen Tercihlerine Etkisi: Diyarbakır ve Tokat Örneği. Ekev Akademi Dergisi, 15(49), 271-292.

Rose, R., \& McAllister, I. (1990). The Loyalties of Voters: A Lifetime Learning Model. Sage Publications.

Schiffman, L. G., Konuk, L. L., \& Wisenblit, J. (2010). Consumer Behavior. Prentice Hall.

Sherman, E., Schiffman, L. G., \& Thelen, S. T. (2012). Young Voter's Trust of Information and Media Sources: The 2008 U.S. Presidential Election. Journal of Political Marketing, 11(1), 246-264.

Shi, T. (2001). Cultural Values and Political Trust A Comparison of the People's Repuclic of China and Taiwan. Comparative Politics, 33(4), 401-419. 
Sipahi. B., Yurtkoru. E. S., \& Çinko. M. (2006). Sosyal Bilimlerde SPSS'le Veri Analizi. İstanbul: Beta Yayınları.

Tan, A. (2002). ilke ve Uygulamalarıla Politik Pazarlama. Papatya Yayınları.

Tek, Ö. B. (2006). Pazarlamada Değer Yaratmak. İstanbul: Hayat Yayınları.

Tek, Ö. B., \& Özgül, E. (2013). Modern Pazarlama Illkeleri Uygulamalı Yönetimsel Yaklaşım (4. b.). İzmir: Birleşik Matbaacılık.

Uztuğ, F. (2004). Siyasal Iletişim Yönetimi (3.b.). İstanbul: Mediacat Kitapları.

Vecchione, M., \& Caprara, G. V. (2009). Personality Determinants of Political Participation: The Contribution of Traits and Self-Efficacy Beliefs. Personality and Individual Differences, 46, 487-492.

Yorke, D. A., \& Meehan, S. A. (1986). ACORN in the Political Market Place. European Journal of Marketing, 20(8), 63-76. 


\title{
A Study on Determining Political Satisfaction and Trust Levels of Voters in the Post-Election Period
}

\author{
Extented Summary
}

\begin{abstract}
Purpose and Significance
Ensuring that voter preferences are shaped in favor of a particular political party and candidate is the main purpose of each political party and candidate in the political market in which they compete. In the fierce competition that exists in the political market, success depends on the correct determination of the needs and wants of the voters. The power required to provide outputs for the areas needed by the society will emerge in line with the decision of the society, which is also composed of voters, through the elections. Therefore, it is a prerequisite for success that political parties and candidates explain their ideas, projects and goals to the public in the best way possible. Achieving this success depends on the effective execution of political marketing efforts. In this context, political marketing includes practices aimed at ensuring that voters make the most appropriate political choice and fully satisfying their political needs. The ultimate goal of political marketing is to satisfy the preferences of the voters through political product mixes that are suitable for the wishes and needs of the voters.
\end{abstract}

The relationship between politics and trust is one of the most discussed issues in politics. Distrust of politics and politicians stands out as one of the most common problems faced by contemporary democratic regimes. According to Mortimore (2003: 119), the level of trust of individuals in politicians is lower than that of professionals working in any institution or public and private sector employees. According to Anderson and Lotempio (2002: 348), there is a relationship between political trust and election results, and voters who vote for the winning candidates in the elections have a higher political trust than those who do not. With in the scope of political trust, the confidence levels of young voters are lower than those of older voters, and features such as insecurity and negative perspectives cause young voters to move away from policies for elections (Dermody and Lloyd, 2004: 203). Another reason for the emergence of political distrust is that the public finds the performance of political institutions as a whole inadequate. Another important reason stems from the citizens' belief that there are widespread injustices and injustices (bribery, nepotism, corruption, etc.) in the management process. The belief that the administration is under the influence of large 
interest groups and that the influence of ordinary citizens is limited erodes the trust of individuals in the system (Akgun, 2007: 140). Another important point regarding political trust is the differentiation of trust levels towards local administrators and central administrators in the presence of voters. Voters not only determine governments with democratic elections, but also determine local decision-making bodies such as mayor / council members at local level. Although the expectations from the local administrations and the expectations from the government are different from each other, the dissatisfaction felt towards one of them damages the level of trust of the voters in politics. A democratic political system cannot survive for long without the support of the majority of the population. Democracy continues its life depending on the trust of the citizens in their government, when this level of trust is damaged or decreased, it is thought that the entire political system under the administration of the government will be threatened (Miller, 1974: 1001). For this reason, it is recommended that political parties and candidates develop a long-term and trust-based relationship with the voters in order to maintain the functioning of democracy and the political system.

This study aims to analyze the political trust and satisfaction levels perceived by voters towards political parties and candidates in the post-election period from a political marketing perspective. Within the scope of the study, the concepts of political trust and political marketing were defined and an area research was carried out in Kirklareli after the local elections held on March 31, 2019 in order to achieve the determined purpose.

\section{Method}

The main purpose of this study is to determine the political trust and satisfaction levels of the voters and to evaluate them within the scope of political marketing. The phenomenon of political trust mentioned in the study; consists of terms of voters' trust in politics and institutions that can be defined as non-political (judiciary and media). Determining the political trust and satisfaction levels perceived by the voters enables the research to be structured as "descriptive" for the current position of a particular phenomenon. Although the population of the research consists of individuals who are voters in Kırklareli, the research was planned within the scope of a sample. In accordance with the purpose of the research, the sample was formed from individuals who had the right to vote in the Local Administrations General Election on March 31, 2019 in Kirklareli Province. In determining the sample size, the formula " $n=N t^{2} p . q / d^{2}(N-1)+t^{2} p . q$ " was applied because the size of the target population was known (Aytug \& Ozguven, 2011, 53). In the related formula, the confidence level was accepted as $95 \%(t=1.96)$ and the voter's participation rate in the elections was accepted as $84.37 \%$, which is the country-wide election participation rate. 
Although the value obtained as a result of the formula was found to be 202, it was aimed that the sample size would reach higher numbers and the application was realized with 340 voters. The field study of the research was carried out between 10/08/2021 and 22/08/2021 in Kırklareli Central District with the voters easily reached by sampling. In the evaluation of the findings for the stated purpose of the research, hypotheses were used. The hypotheses of the research are as follows:

H1: The level of political trust perceived by the voters differs significantly in terms of demographic characteristics.

$\mathrm{H} 2$ : The level of trust perceived by the voters towards institutions differs significantly in terms of demographic characteristics.

H3: The level of political satisfaction perceived by the voters differs significantly in terms of demographic characteristics.

The data of the research were collected through a questionnaire prepared in accordance with the purpose of the research. The questionnaire form is planned in two parts and there are 23 statements in total. In the preparation of the questionnaire form; statements about political trust and trust in institutions were obtained by using the works of Anderson and Lotempio (2002), Aberbach and Walker (1970), Shi (2001), Li (2004), Akgun (2001, 2007). Expressions of political satisfaction were evaluated within the scope of "satisfaction with the preferences in the general and local elections". The data obtained within the scope of the research were transferred to the SPSS 20.0 package program, forty-four erroneous questionnaires were excluded, and the findings were interpreted by performing statistical analyzes with the data of 296 voters. The statements in the first part of the questionnaire were prepared using a "Likert-type" scale in the range of 1-Strongly Disagree...5-Strongly Agree.

\section{Findings}

In the light of the findings obtained during the research process voters think that they are not cared about by the politicians $(\bar{x}=1.80)$, the politicians are not transparent towards them $(\bar{x}=2.14)$, they are not happy to be remembered only during the election periods $(\bar{x}=4.09)$, therefore, their trust level in politicians is quite low $(\bar{x}=3.78)$. In addition, voters feel that both the ruling and opposition parties underestimate their opinions $(\bar{x}=2.38 ; 2.03)$, thus, their satisfaction level with the general political atmosphere in the country $(\bar{x}=1.94)$ is low. It is evaluated that the voters tend to vote for the next election $(\bar{x}=1.99)$ and the level of satisfaction with the candidate or political party preferred in the previous elections $(\bar{x}=3.24$; $3.13)$ is in a relatively positive position. If the subject is explained for the voters' confidence 
assessments regarding the institutional structure of the country, There is a low level of participation in gender equality of opportunity $(\bar{x}=2.30)$, independence of the media $(\bar{x}=1.78)$ and the functioning of the justice system $(\bar{x}=1.77)$. When the general satisfaction of the voters in terms of their economic views is examined; when they compare themselves to the previous year, they feel worse economically $(\bar{x}=1.76)$, It is seen that the thought that life is getting more expensive $(\bar{x}=4.53)$ and thus the level of satisfaction with their life $(\bar{x}=2.70)$ is relatively low. Voters' perceptions of political trust $(\bar{x}=2.05)$ and trust levels towards institutions $(\bar{x}=1.78)$ are quite low. The political satisfaction levels of the voters $(\bar{x}=3.19)$ are relatively high and it is seen that they have a perception of being satisfied with their vote preferences in the previous election.

It is seen that the demographic characteristics of the voters create significant differences in their perceptions of the dimensions of political satisfaction and trust in institutions. The first significant difference obtained is between the political satisfaction levels of female voters and male voters. When the reason for the related difference is examined; It is seen that female voters have a higher level of political satisfaction than male voters. There is a significant difference between the income levels of the voters and their perceived political satisfaction. It was determined that the reason for the significant relationship was the fact that voters without income felt higher political satisfaction than voters with 6001£ per month or more. The marital status of the voters creates a significant difference in terms of the level of trust in institutions. Single voters trust institutions less than married voters. Another significant difference obtained within the scope of the dimension of trust in institutions was obtained in terms of the education levels of the voters. The relevant significant difference is due to the fact that the trust perceptions of the graduate and undergraduate level voters towards institutions are quite low compared to the primary school graduate voters. No significant difference was found in the analyzes carried out regarding the political trust dimension. Although this situation is very thought-provoking, there is a situation where the political perceptions of the voters participating in the study, regardless of their demographic characteristics, meet at a common point and occur at a very low level.

\section{Discussion and Conclusions}

This study, in which the data of 296 voters were evaluated by means of a questionnaire consisting of 23 statements in the province of Kırklareli in the post-Local Administrations General Election held on March 31, 2019, aimed to determine the political trust and satisfaction levels of the voters and to determine whether there is any significant difference in terms of demographic characteristics. In the light of the data obtained, it has been determined that the voters have very low and negative perceptions towards politics and 
politicians. Voters think that politicians do not care about themselves and that the words and promises announced before the election are quickly forgotten by politicians, and therefore, their level of trust in politicians is at a very low level. In addition, voters state that politicians do not act transparently towards them, and they do not consider it appropriate to remember themselves only during the election period. Confidence levels towards institutions, which include perceptions towards the media and the justice system, were also found to be quite low, similar to the levels of trust towards politicians. Despite the fact that the level of trust of the voters towards the political and institutions is quite low, the level of satisfaction with the voting preferences in the previous election is relatively high. The result obtained is similar to the result of the study carried out by Akgun (2007) and Li (2004). At the same time, Anderson and Lotempio (2002) state that the voters of the candidate who lost the election have a lower level of trust than the voters of the candidate who won the election, explaining that the phenomenon of political trust has important effects on the election results.

As a result; with the field research carried out, it has been determined that the level of trust of the voters, who determine the direction of political life with their votes, towards politics, politicians, political parties and institutions is quite low. For this reason, including before and after the election periods, political parties and candidates should apply a trust-based "political relational marketing approach" towards voters, and avoid promises and promises that will damage confidence and create the perception that they cannot be reached in the pre-election period. In order to ensure political trust, voters should be constantly informed about the activities, a clear and transparent management model should be established, and a sense of trust should be created in the voters through negotiations where voter participation is ensured. 